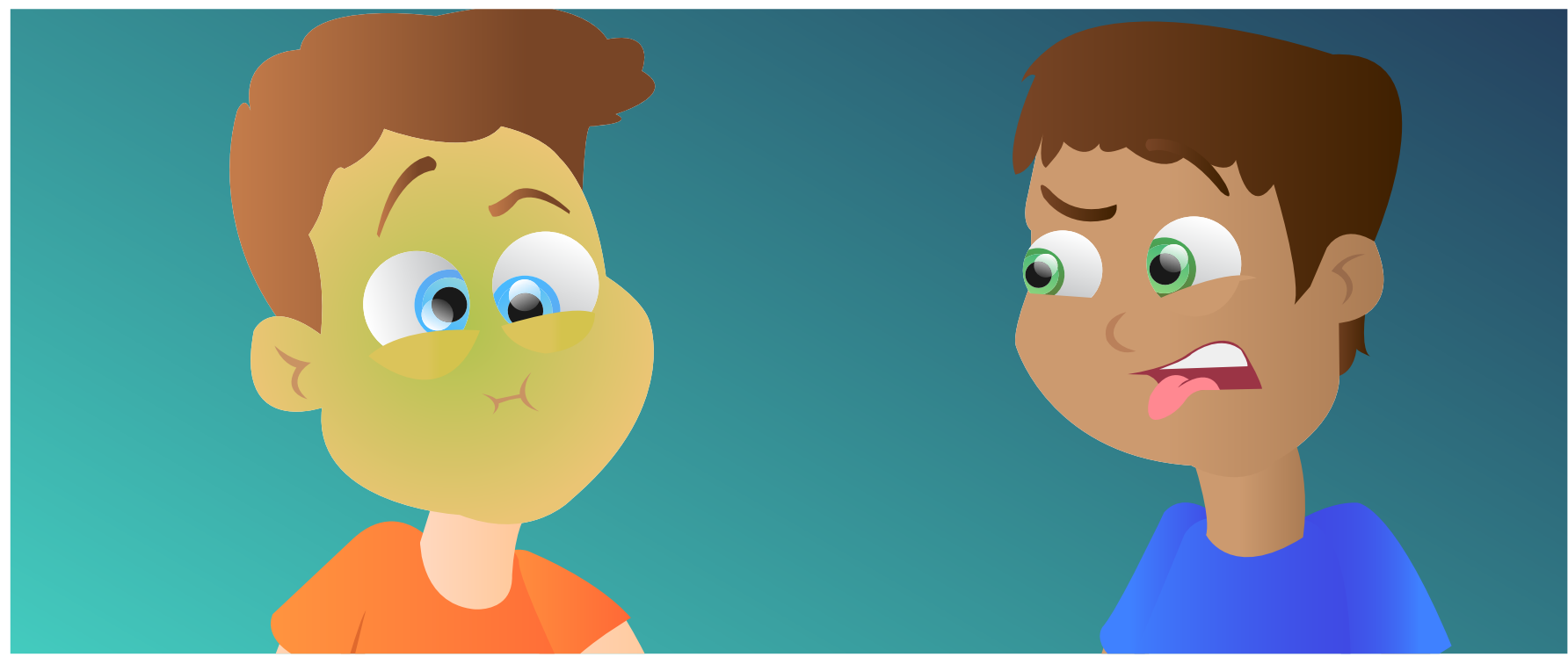

\title{
HOW DO WE FEEL THE EMOTIONS OF OTHERS?
}

\section{Giacomo Rizzolatti ${ }^{1,2}$ and Fausto Caruana ${ }^{1 *}$}

${ }^{1}$ Unit of Neuroscience, University of Parma, Parma, Italy, ${ }^{2}$ Institute of Neuroscience, Consiglio Nazionale delle Ricerche (CNR), Parma, Italy

\section{REVIEWED BY:}

CHAMPIONS OF SCIENCE, CHABOT SPACE AND SCIENCE CENTER 12-15 YEARS OLD
When you see your friend disgusted to the point of vomiting, or laughing until it hurts, you immediately experience what your friend feels. Why do we feel the emotions of others around us? Neuroscience research (the study of the brain) has shown that the brain is equipped with special cells called mirror neurons that directly project information about others' behavior into the regions of our own brain that process emotions. This mechanism shows that others' emotions are not detected only by the visual part of the brain but they also activate our own emotional responses, allowing us to understand and automatically transmit the same information to others. This is an incredibly fast and efficient way to communicate!

\section{EMOTIONAL EXPRESSIONS AND COMMUNICATION}

Humans and animals share the ability to communicate their emotions with others through face and body expressions. The scientific study of emotional expressions started with the work of Charles Darwin, in the late 1800s. In his bestseller "The Expression of the Emotions in Man and Animals," Darwin stated that, regardless of our culture, all humans have the same emotional expressions. More interestingly, similar expressions are also common to different animal species. 


\section{FIGURE 1}

Upper panel: The left side of the human brain.

The colored part of the brain shows the location of the insula. The anterior (front) part of the insula, active during both the experience of disgust experience and when disgust is observed in others, is colored in red. The posterior (back) insula, in yellow, is involved in other sensory functions. Lower panel: The insula became active when study participants observed the expressions of expressions in these short movies. In these short movies, the actors leaned forward to sniff at the content of a glass, and then they showed either a disgust, pleasure, or neutral expression (modified from [1]).
The similarity between human and animal emotions is still a matter of debate. When we try to interpret animal emotional behavior, we need to look at the behaviors that are shared by humans and animals, while also keeping in mind that many emotional behaviors are unique to humans. Researchers who study animal behavior recognize that some animals show a number of human-like emotional behaviors, including disgust and happiness. For this reason, it has been suggested that while some emotions are largely shaped by our culture and society, many other emotional behaviors are shared by humans and animals. Notably, just like Darwin wrote, such similarity between human and animal emotions makes a lot of sense, because Darwin believed that emotions trigger actions that help both humans and animals react to challenges in their environments.

Expressions of disgust, for example, cause reactions that result in reduced contact between the mouth and a disgusting substance, and these expressions remind the brain of the act of vomiting (Figure 1). According to Darwin, our
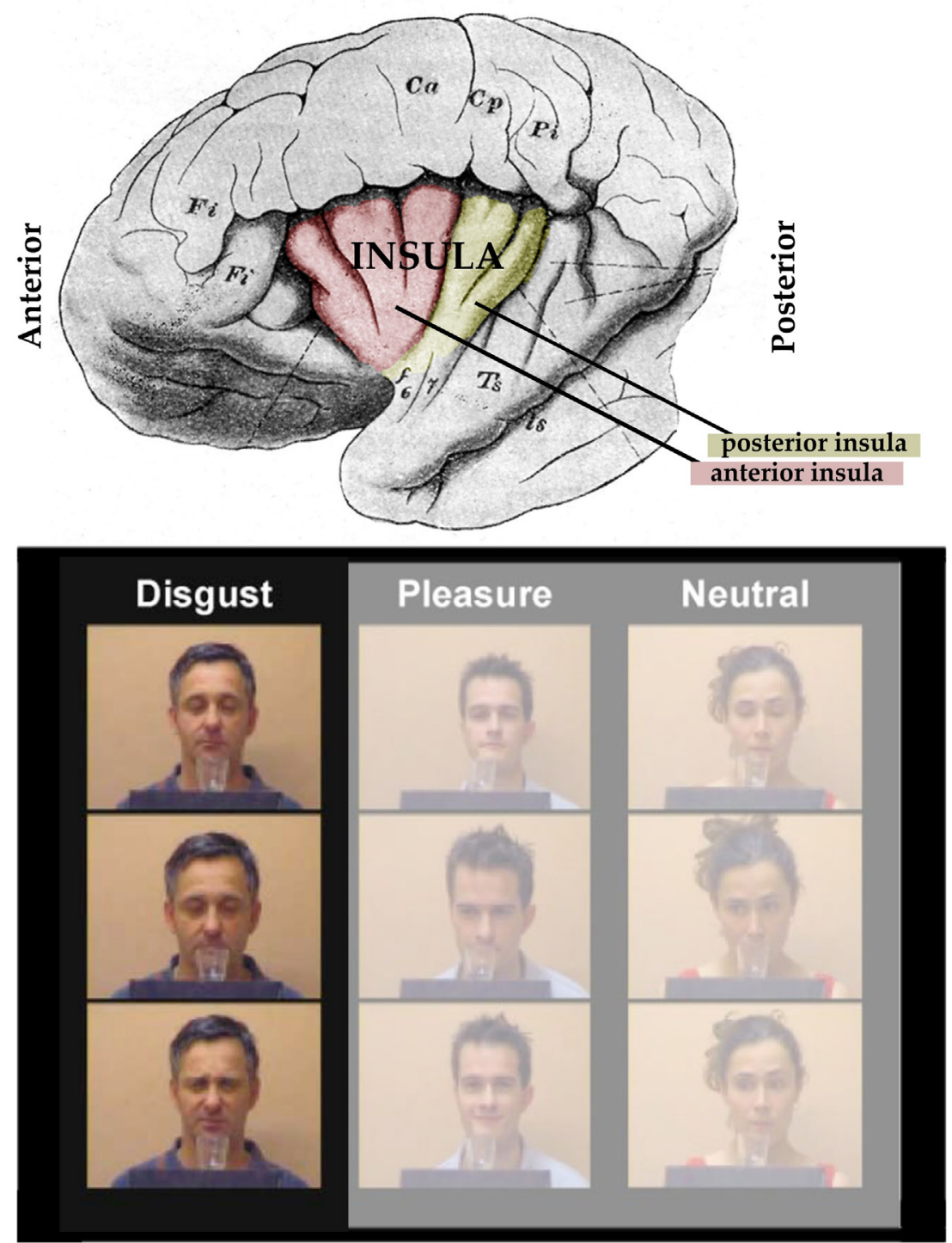

FIGURE 1 
ancestors' emotions were so often followed by the same movements that each time we feel an emotion we automatically produce a corresponding facial expression or bodily movement.

One of the reasons why we inherited emotional expressions is because they play a role in communication. The expression of disgust is efficient way to indicate to our friends, without using language, that they'd better not eat the same food we ate. Laughing, in contrast, is a joyful emotion that comes from the sound of friendly play among friends, and it indicates positive interactions between people. Understanding these expressions and communicating them to other members of the social group is very important for social life. In the case of disgust, for example, facial expressions help us to avoid the risk of eating rotten food, and to transmit the same information to our friends. How does our brain accomplish this task?

\section{THE DISCOVERY OF MIRROR NEURONS}

Surprisingly, one of the most important mechanisms that we use to understand and react to others' emotions is not really all that complicated: it depends on the activity of parts of the brain usually involved in the control of our own actions and emotions. In the 1990s, researchers discovered that when we

\section{NEURONS}

Nerve cells in the brain that encode information and transmit electrical signals to other neurons.

\section{INSULA}

A region buried deep in the folds of the brain that is involved in a variety of functions, including emotions such as disgust.

\section{ELECTRICAL}

\section{STIMULATION}

Applying very small quantities of electricity in the brain to trigger the main function of the stimulated brain region. For example, stimulating the motor system makes the subject move, whereas stimulating emotional regions triggers specific feelings and emotions. observe another person performing an action, this event is detected by both the visual part of the brain and also the motor part, i.e., the part of the brain that typically controls our movements [2]. The motor system is equipped with specific neurons (brain cells) that have a double function. Like other neurons in the motor part of the brain, motor neurons help us perform our own actions, such as grasping a glass of water. However, different from other neurons in the motor part of the brain, these neurons are also activated when we observe the same actions performed by others! Since these neurons mirror the observed action of another person in our own motor system, they are called "mirror neurons" (Figure 2). All we have to do is observe an action in another person in order to trigger a representation of the same action in our own brains; and what is especially interesting is that the same mechanism also applies to emotions.

\section{BOTH OF US DISGUSTED IN MY INSULA!}

Emotions are not controlled by the motor system: disgust, for example, depends on a deep and mysterious part of the brain called the insula (Figure 1, red and yellow areas). For many years, the insula remained a mysterious island, buried deep in the folds of the brain. Thanks to recent advances in technology, scientists have started to investigate its role in our emotional life. Electrical stimulation of this area in the brains of monkeys showed that part of the insula regulates behaviors related to eating food: when this part of 


\section{FIGURE 2}

Mirror neurons are a specific set of neurons that are active when we perform specific actions or feel certain emotions and are also active during when we observe of the same actions/emotions in others.

These neurons transform visual information about others' actions and emotions into experiences in our own brains. This was originally discovered in the motor system. However, recent research shows that this mechanism is a general principle of functioning of the social brain. The figure depicts a typical test for studying mirror neurons.

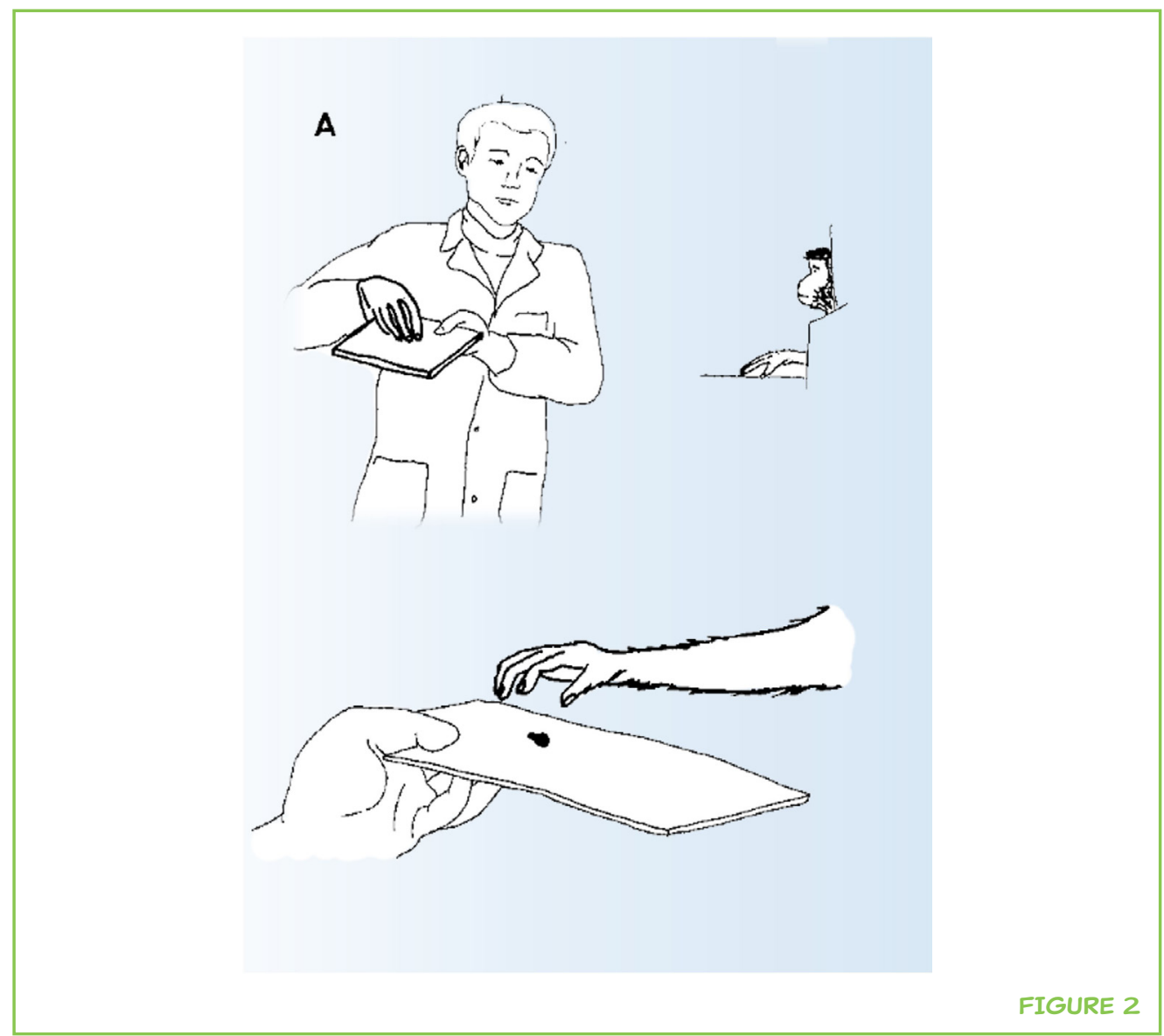

the brain is stimulated, the animal performs mouth movements like chewing and swallowing. If the stimulation is applied to another area of the insula nearby, however, the animal's face will express a variety of disgust expressions: grimaces characterized by the curling of the upper lip and the wrinkling of the nose, vomiting, nausea, and even more complex disgust behaviors such as throwing its favorite food away, or spitting it out [3]. Similar results have also been reported in humans whose brains are stimulated during brain surgery.

Further studies [1] in healthy humans showed that the same part of the insula involved in the experience of disgust is also active when we observe another person smelling a disgusting odor, or tasting a disgusting flavor (Figure 1, lower panel). In a classic brain scanning study, participants were exposed to disgusting smells, which resulted in an increase of activity in the insula. The same participants were presented with movies showing actors expressing disgust or pleasant expressions. When watching actors express disgust, the same part of the insula was active. Your disgust is directly mapped in my insula! Additional evidence comes from studies on brain-damaged patients: when the insula is removed, people have trouble both with experiencing disgust and with recognizing disgust expressions in other individuals. Especially interesting is the case of a patient who, after removal of the insula, was no longer able to recognize disgust in others' faces or from emotional sounds. The difficulty recognizing others' disgust was mirrored by a similar change in the patient's 
NEUROSCIENCE

An area of scientific study aimed at understanding the structure and functions of the human and animal nervous system, including the brain.

\section{FUNCTIONAL}

MAGNETIC

RESONANCE

IMAGING (FMRI)

A technique that measures brain activity by estimating the amount of blood flow. When a brain region is in use, there is more blood flow to the region.

\section{EPILEPSY}

A brain disorder characterized by sudden episodes of an excessive increase of brain electrical activity (epileptic seizures). This can be restricted to some brain regions, or involve the whole brain. It can lead to vigorous shaking and convulsions. own experience: he was unable to experience disgust. Even more interesting is another case of a patient who had serious damage to the insula. When the patient saw a set of pictures of emotional expressions, he was able to name all of them, except he could not name the picture of disgust. When the same patient saw some disgusting food, he did not feel disgust either, and even pointed to the food saying: "delicious"!

The fact that the very same region of the brain that controls my disgust is also active when I see your disgust explains why disgust is so contagious: the mirror mechanism for disgust transforms the visual information about our disgusted friend into my own feeling of disgust. If this activation is strong enough, I react by performing the same expression, which then transmits the same information to other members of the group. What an incredibly fast way to communicate within a group!

\section{WHY IS LAUGHTER CONTAGIOUS?}

Laughter is more contagious than disgust. Laughter is a social behavior aimed at building a social connection with others, and it is often produced, and grows, within groups. Psychologists say that we laugh about 17 times per day, but the frequency of laughing is even higher during conversations. The best stimulus for laughter is another person laughing [4]. Although we laugh all the time, however, laughter is still a mysterious topic in neuroscience (the study of the brain). Since laughing is a social behavior, it is quite difficult to get people laughing during an experiment. In addition, laughter involves several movements, including facial expressions. These movements make it very challenging to study laughter using brain-imaging techniques such as functional magnetic resonance imaging (fMRI). During fMRI experiments, a scanner takes photos of the brain showing the amount of activity in different parts of the brain. If the participants move their heads due to laughter during the experiment, these photos become very fuzzy and scientists can no longer get an accurate image of brain activity. Due to these reasons, our knowledge about the brain mechanisms that cause laughter is still very limited.

A very recent study on laughter was performed on epileptic patients who had to go through surgery to identify the part of the brain that is causing the epilepsy. Neurosurgeons inserted electrodes into the brains of these patients to monitor the brain activity during epileptic seizures. During this procedure, scientists can also try to identify brain regions responsible for specific functions by stimulating different parts of the brain. During the stimulation, the patient is awake, sitting upright on the hospital bed. Depending on which part of the brain is stimulated, the stimulation can cause motor behaviors (movements), or auditory, somatosensory, visual, or gustatory sensations. When part of a brain region called the anterior cingulate cortex (ACC) was stimulated, some patients started to laugh (Figure 3) [5]. This is particularly 


\section{FIGURE 3}

Upper panel: The figure shows the right side of the human brain from what is called a medial perspective-imagine the left side of the brain was removed, allowing us to see the inside of the right side of the brain.

Electrical stimulation of the anterior cingulate cortex (ACC) caused a burst of laughter, often accompanied by happiness. The yellow dots indicate the areas of the brain from which laughter was caused when the electrical stimulation was applied (modified from Ref. [5]).

The stimulation of brain areas represented by the black dots caused different reactions that are not related to emotions. Lower panel: Four different time points of the effect caused by the electrical stimulation of the ACC, from the starting point of the stimulation

(1) to the induced

laughter (4).
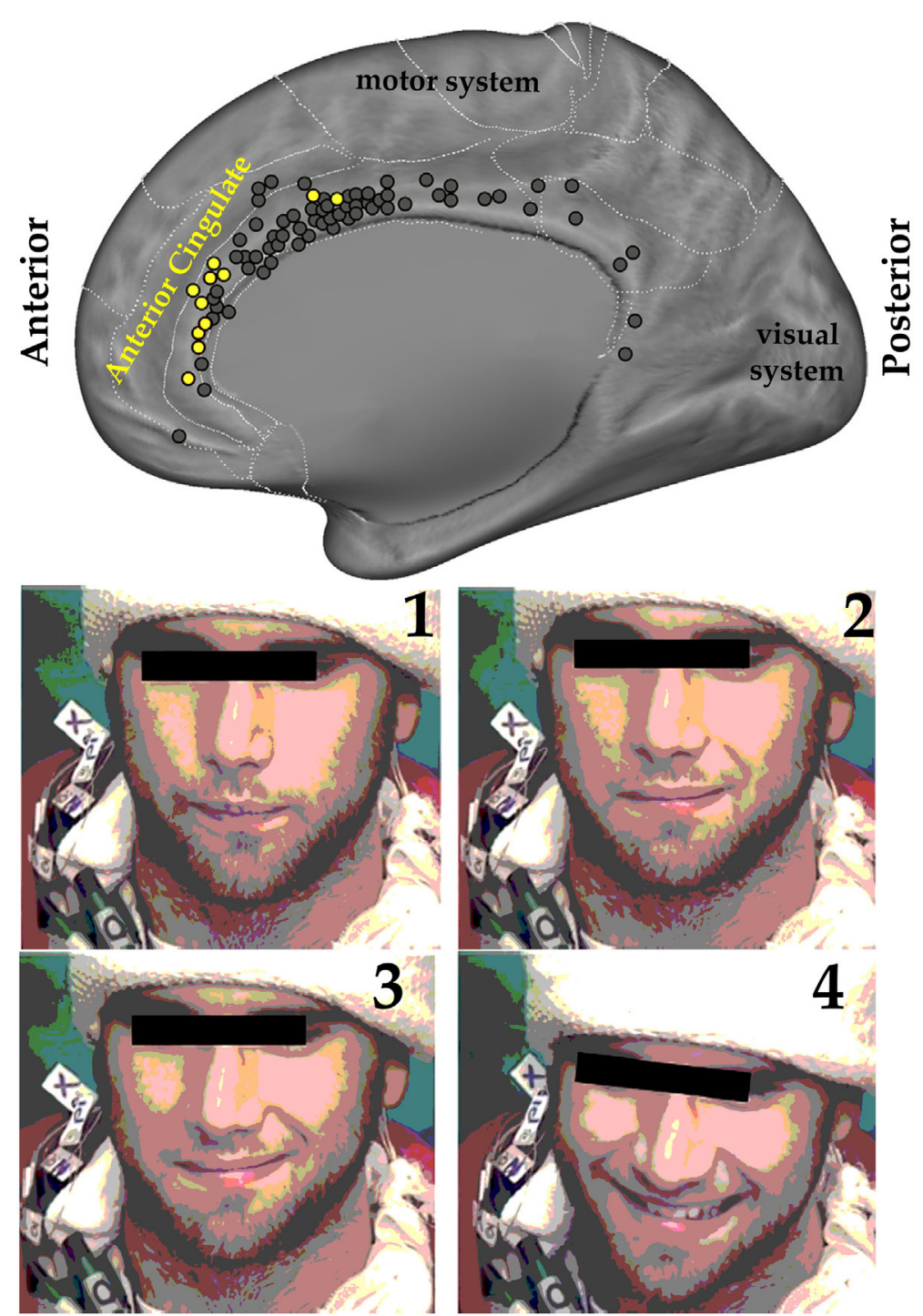

FIGURE 3

interesting because this brain region is commonly active during our experience of positive events, such as humor, positive emotional expressions, or pleasant touch. Interestingly, seeing someone else laugh or display happiness also activates the ACC, the same area where the electrical stimulation causes laughter. It is important to note that the ACC is not part of the visual system in the brain, which means that, when we begin to laugh after experiencing others laughing, our laughter is not only caused by seeing the other person laughing, an experience of another person laughing also directly activates our brain region for laughter. This is the mirror neurons at work!

There are many consequences of this mirroring process. Laughing in the company of others increases chemicals in our brains that make us feel happy. These chemicals are known to create a positive mood. When we lack these chemicals, it can increase stress, loneliness and, in the worst cases, depression. Therefore, contagious laughter through the mirroring process is a natural 
cure for a bad mood, and this is the reason why it is a good thing not to let people suffer alone, but rather to give a laugh in their company.

\section{REFERENCES}

1. Wicker, B., Keysers, C., Plailly, J., Royet, J. P., Gallese, V., and Rizzolatti, G. 2003. Both of us disgusted in My insula: the common neural basis of seeing and feeling disgust. Neuron 40:655-64. doi:10.1016/S0896-6273(03)00679-2

2. Rizzolatti, G., and Sinigaglia, C. 2016. The mirror mechanism: a basic principle of brain function. Nat. Rev. Neurosci. 17(12):757-65. doi:10.1038/nrn.2016.135

3. Jezzini, A., Caruana, F., Stoianov, I., Gallese, V., and Rizzolatti, G. 2012. Functional organization of the insula and inner Perisylvian regions. Proc. Natl. Acad. Sci. U.S.A. 109:10077-82. doi:10.1073/pnas.1200143109

4. Provine, R. R. 2000. Laughter: A Scientific Investigation. New York: Viking.

5. Caruana, F., Avanzini, P., Gozzo, F., Francione, S., Cardinale, F., and Rizzolatti, G. 2015. Mirth and laughter elicited by electrical stimulation of the human anterior cingulate cortex. Cortex 71:323-31. doi:10.1016/j.cortex.2015.07.024

SUBMITTED: 07 November 2016; ACCEPTED: 28 June 2017;

PUBLISHED ONLINE: 18 July 2017.

EDITED BY: Robert T. Knight, University of California, Berkeley, United States

CITATION: Rizzolatti G and Caruana F (2017) How Do We Feel the Emotions of Others? Front. Young Minds 5:36. doi:10.3389/frym.2017.00036

CONFLICT OF INTEREST STATEMENT: The authors declare that the research was conducted in the absence of any commercial or financial relationships that could be construed as a potential conflict of interest.

COPYRIGHT @ 2017 Rizzolatti and Caruana. This is an open-access article distributed under the terms of the Creative Commons Attribution License (CC BY). The use, distribution or reproduction in other forums is permitted, provided the original author(s) or licensor are credited and that the original publication in this journal is cited, in accordance with accepted academic practice. No use, distribution or reproduction is permitted which does not comply with these terms.

\section{REVIEWED BY}

\section{CHAMPIONS OF SCIENCE, CHABOT SPACE AND SCIENCE CENTER, 12-15 YEARS OLD}

Champions of Science exclusively serves underserved middle school students from the Oakland Unified School District. Champions of Science develops students' knowledge and excitement about STEM and gives participants exposure to various careers. 


\section{AUTHORS}

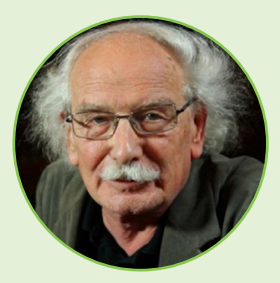

\section{GIACOMO RIZZOLATTI}

Professor Emeritus of Human Physiology at the University of Parma and responsible of the CNR-URT Neuroscience of Parma. The main focus of his research concerns the motor system and its role in cognitive functions. He is the discoverer of the mirror neurons. He is a Member of Academia Europaea, of Accademia dei Lincei, of the Institute de France (Académie des Sciences), Honorary Foreign Member of the American Academy of Arts and Sciences and Foreign Member of National Academy of Science (USA). He is an honorary member of the Italian Society for Neuroscience and Italian Physiological Society. He has received many awards among which the most recent are: "Feltrinelli Prize for Medicine" of Accademia dei Lincei, prix IPSEN, Neuroplasticity, the Grawemeyer Award for Psychology, Prix Signoret, Neuropsychology, Fondation IPSEN, and the Brain Prize from Lundbeck Foundation. He received Honorary Degrees from the University Claude Bernard of Lyon, the University of St. Petersburg, the University of Sassari, KU Leuven, and University of St. Martin, Buenos Aires.

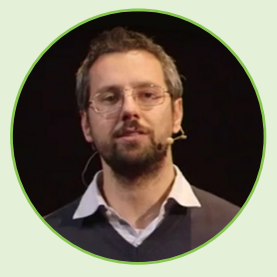

\section{FAUSTO CARUANA}

Trained as a philosopher and specialized in neuroscience at the University of Parma. The main focus of his research concerns the mirror system and the neural basis of social cognition, by means of a multidisciplinary approach including intracranial recording, in collaboration with the Epilepsy Surgery Center Niguarda Hospital, in Milan. His major research interests lie in the relationships between the motor system and cognitive and affective functions, and in the theoretical aspects of embodied cognition. *fausto.caruana@ unipr.it 